\title{
Neonatal and postneonatal mortality in Germany since unification
}

Ellen Nolte, Angela Brand, Ilona Koupilová, Martin McKee

\begin{abstract}
Background-After unification, the gap in infant mortality rates between the two parts of Germany widened until 1996 before converging. The reasons for these changes have not, so far, been apparent. Objectives-To investigate trends in neonatal and postneonatal mortality in the eastern (the new Länder) and western (the old Länder) part of Germany after unification in 1990 and to identify the scope for further improvement.

Design-Examination of trends in birth weights, birth weight specific neonatal mortality and cause specific postneonatal mortality in the two parts of Germany from 1990 to 1996 and 1997 by analysing routinely available vital statistics data.

Results-In both parts of Germany, neonatal mortality fell considerably, by 33 per cent in the east and 17 per cent in the west, from 4.5 and 3.5 per thousand live births in 1990 to 3.0 and 2.9 in 1997 , respectively. This was attributable to an improvement in survival of infants at all birth weights but especially among those with very low birth weights, accounting for an estimated 83 to 85 per cent of the overall improvement. The birth weight distribution showed a slight worsening in the new and the old Länder with an increase in the proportion of those under $1500 \mathrm{~g}$ and, in the east, a 24 per cent increase in the proportion of high birthweight infants of 4000 and more grams. Trends in postneonatal mortality revealed a worsening of about 32 per cent in the east from 1990 to 1991 followed by a decline of over 50 per cent up to 1997 , leading to comparable mortality rates of 1.8 per thousand live births in the east and 2.0 in the west. While both parts experienced a decrease of 40 to 48 per cent in deaths from all diseases, the decline in deaths because of accidents and injuries was markedly higher in the new Länder although they are still exceeding the western rate by 3.7 per 100000 live births in 1997.

Conclusions-Since unification, the two parts of Germany underwent a complex process that has led finally to convergence of parameters of infant health that are most likely to have been because of improvements in the quality of perinatal care. To improve infant mortality in Germany, policy measures should focus on preventive rather than curative measures as the proportion of very low birthweight babies is increasing in both parts of Germany. (F Epidemiol Community Health 2000;54:84-90)
\end{abstract}

Since the revolution of 1989 , the former German Democratic Republic (GDR) underwent profound social and economic changes. After its integration in the Federal Republic of Germany (FRG) in 1990, it became a market economy within a few months. The transformation was accompanied by a massive economic decline in the first years after unification, which also had enormous consequences for demographic trends. Since 1989, about 1.7 million east Germans left for the west, the birth rate fell by about $60 \%$ in the period from 1989 to 1994 , and the number of marriages and divorces declined sharply. ${ }^{1}$

There were also major consequences for the west. Since unification, western Germany has transferred huge financial sums to the now new Länder (new federal states) to alleviate the effects of adjusting to market conditions, to restructure industry, and to develop infrastructure. ${ }^{2}$ The resulting economic downturn had consequences for all of western Europe.

Change of this scale might be expected to have consequences for health. Researchers have concentrated on the consequences of the political changes in Europe for adult health but there is growing evidence of the effects on children. These present a complex picture, with increases in deaths from injuries in many parts of the region, ${ }^{3}$ but also some improvements in neonatal mortality, which seem to be attributable to improvements in the quality of medical care. ${ }^{4}$

There has been little research undertaken on the consequences of transition for infant health in Germany, although one paper has examined changes in birth weight during the period 1990 to $1992 .{ }^{5}$ It found that the new Länder experienced an increase in extremely low birthweight births $(<1000 \mathrm{~g})$ and, after discussing several possible reasons, concluded that the most important factor may have been the introduction of the western definition of a live birth, which required presence of a heart beat or breathing or a pulsating umbilical cord, compared with the eastern definition of presence of a heart beat and breathing.

In both parts of Germany, infant mortality rates improved after unification. However, the improvement was somewhat greater in the west than in the east, at least until 1996. In the east, it fell from 7.2 per thousand live births in 1990 to 5.5 in 1996 . In the west, the corresponding figures were 7.1 and $5.0 .{ }^{6}$ Consequently, the gap increased from 0.1 to 0.5 per thousand, which is equivalent to 90 additional deaths per year if the western rate had applied in the east in 1996. Further improvement was achieved in 
both parts in 1997 with infant mortality rates in the two parts of Germany becoming identical at 4.9 per thousand.

There are many plausible theories that could explain the gap in infant mortality within Germany between 1990 and 1996. However, there have been no detailed analyses to support any of them. This paper investigates how neonatal and postneonatal mortality have changed in Germany after unification by means of an exploration of routinely available data. Birth weight is considered to be an important measure of the health status of a population and a strong predictor of infant survival, so it separates trends in birth weight distribution that tend to reflect socioeconomic factors from changes in birth weight specific neonatal mortality that more closely reflect access to and quality of medical care.

\section{Methods}

Data were obtained from the Federal Statistical Office Germany (Statistisches Bundesamt) on live births and on deaths during the first year of life by birth weight for 1990 to 1996. Data included all singleton and multiple births, with birth weights aggregated into $100 \mathrm{~g}$ bands from $500 \mathrm{~g}$ up to $5000 \mathrm{~g}$; birth weights less than 500 g were recorded separately. For 1997, only data on infant deaths by cause were available. All causes of death were coded according to the International Classification of Diseases, 9th revision (ICD-9). Data on neonatal and postneonatal mortality from 1970 to 1989 in the old Federal Republic of Germany (FRG) were obtained from the World Health Organisation database, ${ }^{7}$ corresponding data from the German Democratic Republic (GDR) are taken from the mortality tapes of the GDR. ${ }^{8}$

Neonatal and postneonatal mortality were analysed separately, with neonatal mortality relating to deaths occurring within the first 28 days of life, and postneonatal mortality to subsequent deaths within the first year. The distributions of birth weight, and birth weight specific neonatal mortality were calculated for the years 1991 and 1996. Initial inspection demonstrated that there were substantial problems with data on low birthweight births in the east in 1990, with substantially fewer being recorded than would have been expected based on the overall distribution of birth weights. This may have been influenced by the rule that stillbirths less than $1000 \mathrm{~g}$ were not recorded in either part of Germany until 1994. Although we cannot be sure that all problems have been solved, we believe data quality to be considerably better in 1991. As available data on birth weight were aggregated into $100 \mathrm{~g}$ bands, calculation of the mean birth weight was undertaken by giving each band a value corresponding to the midpoint of the band (except for the band $\geqslant 5000 \mathrm{~g}$, which was given the value $5050 \mathrm{~g}$ ).

Trends in postneonatal mortality were examined by cause, again for east and west and for 1991 and 1997. Throughout this paper, the phrase "new Länder" or "east" refers to the territory of the former GDR before unification, including East Berlin, and "old Länder" or "west" to the territory of the old Federal Republic including West Berlin.

Rates were calculated as the number of neonatal or postneonatal deaths in a given year per 1000 live births. Where appropriate, expected rates were calculated by the indirect method of standardisation to adjust for either differences in birth weight distribution or differences in birth weight specific neonatal mortality rates. Analyses were carried out using the Microsoft Excel spreadsheet. ${ }^{9}$

\section{Results}

The changes in neonatal and postneonatal death rates and in numbers of births and deaths in each part of Germany are shown in table 1 . The decline in neonatal mortality in the new Länder was almost twice that in the old Länder and, for these deaths, the gap, which had been one per thousand, almost disappeared. In contrast, the postneonatal death rate fell more rapidly in the west, albeit from a higher initial level, reaching rates similar to those in the east by 1997.

\section{BIRTH WEIGHT DISTRIBUTION}

Other than possible recording artefact, the relatively large decline in neonatal mortality in the east could be attributable to an improvement in the birth weight distribution, decline in birth weight specific mortality, or both. The distributions of birth weight in east and west are shown in figure 1 . The median and mean weight are given in table 2 . The mean birth weight in the new Länder was $12 \mathrm{~g}$ lower than in the old Länder in 1991 (table 2). By 1996,

Table 1 Live births, infant deaths, neonatal and postneonatal mortality in the two parts of Germany: 1990-1997

\begin{tabular}{|c|c|c|c|c|c|c|c|c|c|}
\hline & 1990 & 1991 & 1992 & 1993 & 1994 & 1995 & 1996 & 1997 & $\begin{array}{l}\% \text { decline } \\
1990-97\end{array}$ \\
\hline \multicolumn{10}{|l|}{ Live births } \\
\hline New Länder & 178476 & 107769 & 88320 & 80532 & 78698 & 83847 & 93325 & 100258 & 44 \\
\hline Old Länder & 727199 & 722250 & 720794 & 717915 & 690905 & 681374 & 702688 & 711915 & 2 \\
\hline \multicolumn{10}{|l|}{ Infant deaths } \\
\hline New Länder & 1309 & 849 & 642 & 515 & 490 & 455 & 499 & 485 & 63 \\
\hline Old Länder & 5076 & 4862 & 4350 & 4150 & 3819 & 3598 & 3463 & 3466 & 32 \\
\hline \multicolumn{10}{|c|}{ Neonatal mortality / 1000} \\
\hline New Länder & 4.5 & 4.1 & 4.0 & 3.4 & 3.7 & 3.1 & 3.1 & 3.0 & 33 \\
\hline Old Länder & 3.5 & 3.4 & 3.3 & 3.1 & 3.2 & 3.0 & 3.0 & 2.9 & 17 \\
\hline E-W gap ${ }^{\star}$ & 1.0 & 0.7 & 0.7 & 0.3 & 0.5 & -0.1 & 0.1 & 0.1 & \\
\hline \multicolumn{10}{|c|}{ Postneonatal mortality / 1000} \\
\hline New Länder & 2.8 & 3.7 & 3.3 & 3.0 & 2.6 & 2.3 & 2.2 & 1.8 & 36 \\
\hline Old Länder & 3.4 & 3.3 & 2.7 & 2.7 & 2.4 & 2.1 & 2.0 & 2.0 & 41 \\
\hline E-W gap & -0.6 & 0.4 & 0.6 & 0.3 & 0.2 & 0.2 & 0.2 & -0.2 & \\
\hline
\end{tabular}

*"E" and "W" refer to the new Länder ("east") and the old Länder ("west"). 


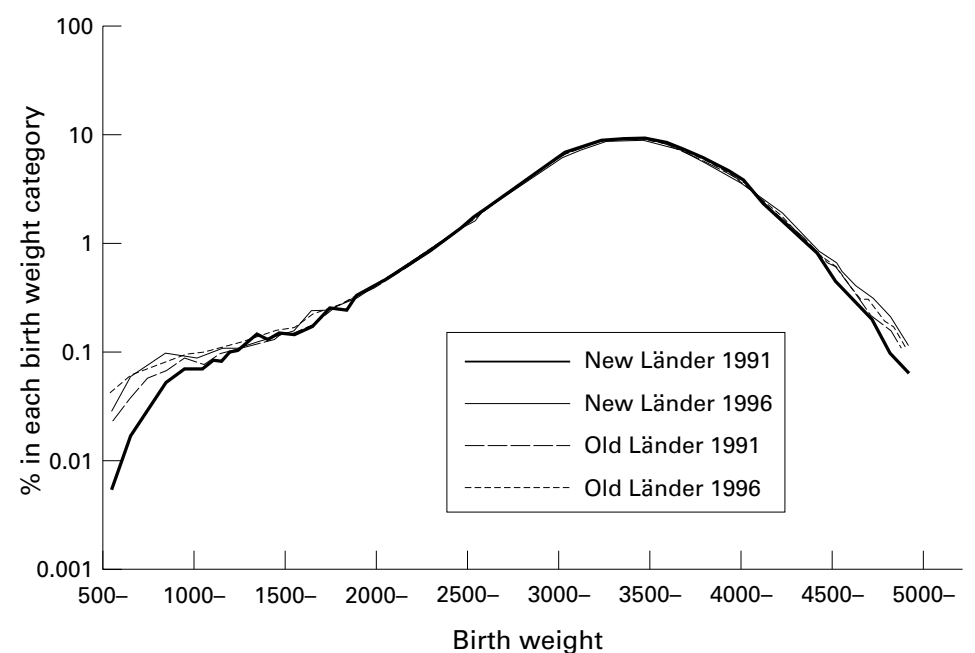

Figure 1 Distribution of birth weight in Germany, 1991 and 1996.

Table 2 Birth weight distribution in the two parts of Germany: 1991 and 1996

\begin{tabular}{|c|c|c|}
\hline & 1991 & 1996 \\
\hline \multicolumn{3}{|c|}{ Median birth weight (g) } \\
\hline New Länder & 3277 & 3314 \\
\hline Old Länder & 3289 & 3299 \\
\hline \multicolumn{3}{|c|}{ Mean birth weight $(\mathrm{g})$} \\
\hline New Länder & 3350 & 3384 \\
\hline Old Länder & 3362 & 3367 \\
\hline \multicolumn{3}{|l|}{$\%<2500 \mathrm{~g}$} \\
\hline New Länder & 5.8 & 5.9 \\
\hline Old Länder & 5.8 & 6.2 \\
\hline \multicolumn{3}{|l|}{$\%<1500 \mathrm{~g}$} \\
\hline New Länder & 0.7 & 0.9 \\
\hline Old Länder & 0.8 & 1.0 \\
\hline \multicolumn{3}{|l|}{$\%<1000 \mathrm{~g}$} \\
\hline New Länder & 0.2 & 0.4 \\
\hline Old Länder & 0.3 & 0.4 \\
\hline \multicolumn{3}{|c|}{$\%$ birth weight not known } \\
\hline New Länder & 0.2 & 0.0 \\
\hline Old Länder & 0.3 & 0.3 \\
\hline
\end{tabular}

mean birth weight in the new Länder had increased by $34 \mathrm{~g}$, while in the old Länder it increased by only $5 \mathrm{~g}$. This had the effect of reversing the relative ranking of the two parts of the country. The percentage under $1500 \mathrm{~g}$ increased in both parts of Germany (table 2). However, as indicated by the birth weight distribution (fig 1), the new Länder experienced an increase in high birthweight infants $(\geqslant 4000$

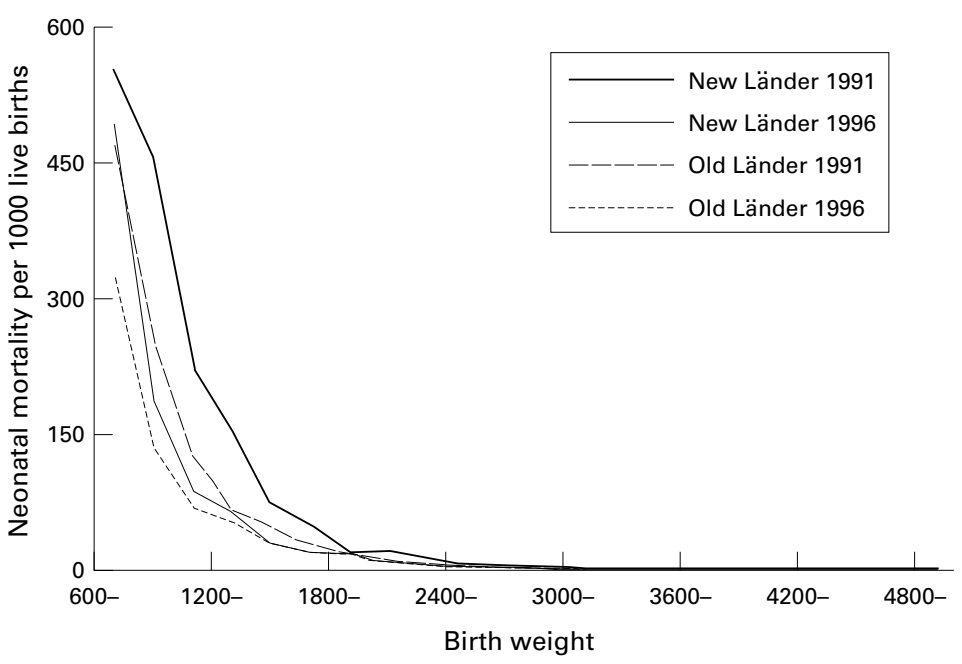

Figure 2 Change in neonatal mortality by birth weight in Germany, 1991 and 1996.
Table 3 Changes in birth weight specific neonatal mortality per thousand live births in the two parts of Germany: 1991 and 1996

\begin{tabular}{cccl}
\hline & 1991 & 1996 & $\%$ decline \\
\hline$<1000$ g & & & \\
New Länder & $494.7(94)^{\star}$ & $371.4(127)$ & 25 \\
Old Länder & $390.0(817)$ & $315.6(873)$ & 19 \\
1000-<1500 g & & & \\
New Länder & $155.7(90)$ & $65.3(33)$ & 58 \\
Old Länder & $83.8(330)$ & $53.4(234)$ & 36 \\
1500-<2000g & $34.4(44)$ & $18.9(22)$ & 45 \\
New Länder & $25.1(210)$ & $19.1(173)$ & 24 \\
Old Länder & $11.8(50)$ & $5.8(20)$ & 51 \\
2000-<2500 g & $7.2(196)$ & $5.3(144)$ & 26 \\
New Länder & \multicolumn{3}{l}{} \\
Old Länder & &
\end{tabular}

${ }^{\star}$ Number of deaths.

g) as well, from 9.6 per cent in 1991 to 11.9 per cent in 1996.

\section{NEONATAL MORTALITY}

Changes in birth weight specific neonatal mortality are shown in figure 2. In 1991, mortality at very low birth weights was higher in the east than in the west but by 1996 the gap had narrowed considerably (table 3 ). The unusual low proportion of neonatal deaths in the very low

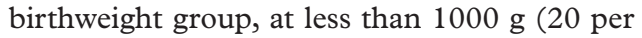
cent in 1991 and 1992 as compared with 35 per cent in the west) raises the probability of under-reporting. Thus, in the subsequent analyses, births under $1000 \mathrm{~g}$ were excluded.

The impact of changes in the birth weight distribution can be seen by adjusting the mortality rates in 1996 for birth weight and excluding births of unknown weight and under 1000 g. In the new Länder, the neonatal mortality in 1991 was 3.03 per thousand, which — based on changes in birth weight distribution onlywould be predicted to become 3.04 in 1996. In the old Länder the corresponding figures are 2.03 and 2.12 (table 4 ). Thus the effect of the change in birth weight distribution alone would have been to cause a slight deterioration in neonatal mortality in both the east and the west.

There have, however, been marked changes in survival at each birth weight category. In 1991, neonatal mortality rates were higher in all birth weight categories in the new Länder than in the old. The impact of these differences can be seen more clearly by applying the birth weight specific rates seen in the old Länder to the birth weight distribution in the new Länder (again after excluding births of unknown weight and below $1000 \mathrm{~g}$ ). Had the outcomes seen in the old Länder applied in the east in 1991, the rate would have been 2.01 per thousand instead of the observed 3.03 (table 4). This suggests that, had the medical care available in the west been available in the east at this time, neonatal mortality could have been reduced substantially, even allowing for the worse birth weight distribution.

In both parts, birth weight specific mortality rates fell between 1991 and 1996. If the birth weight distribution had been unchanged, improvements in outcome at each level of birth weight would have caused the neonatal mortality rate to have fallen from 3.03 to 1.77 , or 42 per cent in the new Länder and from 2.03 to 
Table 4 Impact of changes in birth weight and birth weight specific neonatal mortality rates on neonatal mortality in the two parts of Germany: 1991 and 1996

\begin{tabular}{|c|c|c|c|}
\hline & & 1991 & 1996 \\
\hline \multirow[t]{2}{*}{ Observed neonatal mortality per $1000^{\star}$} & New Länder & 3.03 & 1.74 \\
\hline & Old Länder & 2.03 & 1.57 \\
\hline \multirow{3}{*}{$\begin{array}{l}\text { Predicted neonatal mortality } \\
\quad \text { applying } 1991 \text { rates to } 1996 \text { birth weight distribution }\end{array}$} & & & \\
\hline & New Länder & - & 3.04 \\
\hline & Old Länder & - & 2.12 \\
\hline \multirow[t]{2}{*}{ applying 1996 rates to 1991 birth weight distribution } & New Länder & - & 1.77 \\
\hline & Old Länder & - & 1.51 \\
\hline applying western rates to eastern birth weight distribution & New Länder & 2.01 & 1.50 \\
\hline
\end{tabular}

$\star$ Excluding births under $1000 \mathrm{~g}$ and births of unknown weight.

1.51 , or 26 per cent, in the old Länder. Data in table 4 thus indicate that, while the outcome for neonates improved considerably in both parts, the improvement was substantially greater in the new Länder. The new Länder did not, however, catch up with the west in 1996 as the actual rate in the new Länder was 1.74 per thousand whereas if the birth weight specific mortality rates seen in the old Länder had been achieved it would have fallen to 1.50 . It should be reiterated that these figures apply only to births greater than $1000 \mathrm{~g}$ for the reasons stated earlier.

Again by applying the 1996 neonatal mortality rates to the 1991 birth weight distribution, but considering all births, it can be seen that changes in birth weight distribution in both parts of Germany contributed only slightly to the fall in neonatal mortality. From this, improvements in survival at each level of birth weight are calculated to account for 83

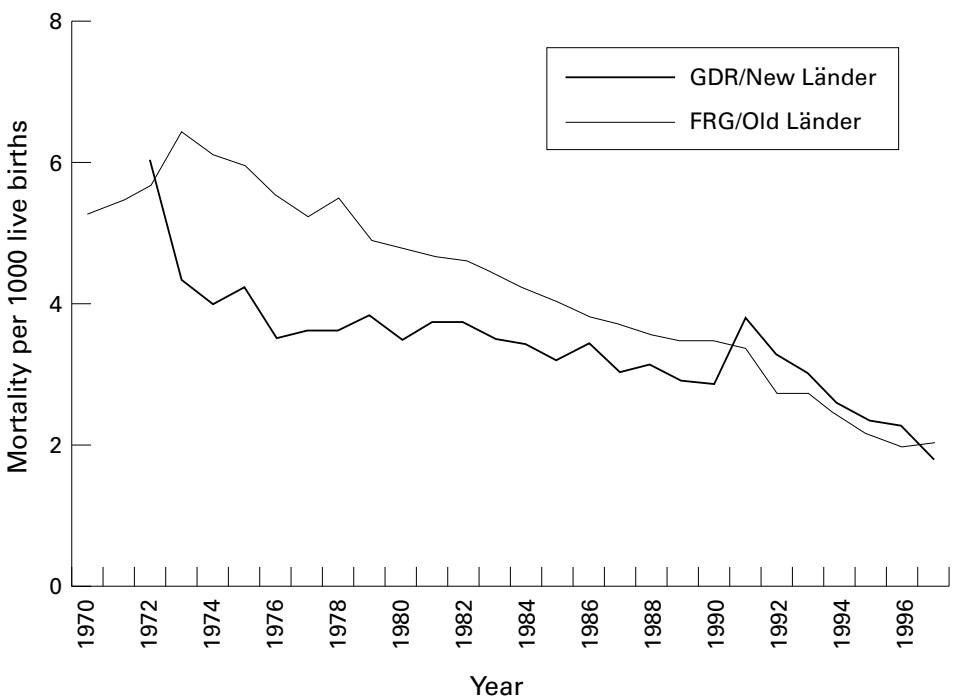

Figure 3 Postneonatal mortality in the former GDR and FRG and the new and the old Länder, 1970-1997. per cent of the overall improvement in the east and 85 per cent in the west.

\section{POSTNEONATAL MORTALITY}

Trends in postneonatal mortality are shown in figure 3. Throughout the 1970s and 1980s, the former GDR had a lower postneonatal mortality than the FRG. There was an increase in postneonatal mortality in the west after 1970, but not in the east. Starting from an even lower rate in 1990, the new Länder first experienced an increase of about 32 per cent up to 3.7 per thousand live births in 1991 that was followed by a decrease of over 50 per cent by 1997 to 1.8 per thousand.

The changes in cause of death in the two parts of Germany are shown in table 5. Taking 1991 as baseline, both parts of Germany experienced a decline in deaths from all diseases, resulting into the new Länder having a considerably lower postneonatal mortality in 1997 (166.6 per 100000 live births $v 190.3$ per 100000 in the west). Deaths classified as attributable to congenital anomalies fell by $60 \%$ in the east. In the west the corresponding decline was $17 \%$, resulting in postneonatal mortality attributable to congenital anomalies that is 1.5 times higher than in the east. Postneonatal mortality because of conditions originating perinatally appears to be substantially lower in the old Länder with the new Länder displaying a slight upward trend since 1996 (table 5).

Regarding the somewhat smaller decline in mortality from "other diseases" in the east it has to be noted that the increase in postneonatal mortality observed immediately after unification was partly attributable to a 63 per cent increase of deaths from "signs, symptoms, and ill-defined conditions" (ICD group XVI). This ICD group was not approved for analysing causes of infant death in the former GDR, ${ }^{10}$ thus the introduction of the western classification system might have had some influence

Table 5 Deaths and death rates per 100000 live births from specific causes in the postneonatal period in Germany: 1991 and 1997

\begin{tabular}{|c|c|c|c|c|c|c|}
\hline \multirow[b]{2}{*}{ Cause of death ${ }^{\star}$} & \multicolumn{3}{|l|}{ Old Länder } & \multicolumn{3}{|l|}{ New Länder } \\
\hline & 1991 & 1997 & $\%$ decline & 1991 & 1997 & $\%$ decline \\
\hline All diseases (ICD 001-799) & $315.1(2276)$ & $190.3(1355)$ & 40 & $319.2(344)$ & $166.6(167)$ & 48 \\
\hline Congenital anomalies (ICD 740-759) & $69.0(498)$ & $57.2(407)$ & 17 & $93.7(101)$ & $37.9(38)$ & 60 \\
\hline Conditions originating in the perinatal period & & & & & & \\
\hline (ICD 760-779) & $41.8(302)$ & $28.2(201)$ & 33 & $45.5(49)$ & $36.9(37)$ & 19 \\
\hline Other diseases (including SIDS) & $185.3(1338)$ & $96.6(688)$ & 48 & $142.0(153)$ & $76.8(77)$ & 46 \\
\hline Accidents and injuries (E800-999) & $18.1(131)$ & $9.3(66)$ & 49 & $54.7(59)$ & $13.0(13)$ & 76 \\
\hline All deaths & $333.3(2407)$ & $199.6(1421)$ & 40 & $373.9(403)$ & $179.5(180)$ & 52 \\
\hline
\end{tabular}

^According to ICD-9 = International Classification of Diseases, 9th revision. SIDS = sudden infant death syndrome. 
on the increase in postneonatal mortality in 1991. The decline in deaths because of accidents and injuries was higher in the new Länder $(76 \%$ v $49 \%)$ although they are still exceeding the western rate by 3.7 per 100000 in 1997.

\section{Discussion}

DATA QUALITY

Comparisons such as this depend upon the quality and completeness of information on size at birth and infant death. Because each birth and death in Germany has to be registered with the local registry office, the numbers that are provided by the Federal Statistical Office are to be seen as, officially, virtually complete. However, completeness also depends on a clear distinction between stillbirths and live born infants who die soon after birth. Until April 1994 stillborn children below $1000 \mathrm{~g}$ were defined as miscarriages and not recorded in the official statistics. Because of changes in the law, stillbirths are now defined as having a weight of at least $500 \mathrm{~g}$, and require the absence of a heart beat, breathing and a pulsating umbilical cord. The implementation of this new definition may depend upon external factors such as the skills of hospital staff in neonatal intensive care and therefore might have had some influence on the completeness of information about live births and deaths in the group below $1000 \mathrm{~g}$. Formal evaluation of the quality of data has not been available but, with this exception, it is generally believed to be good.

However, it has to be considered that the definition of live and stillbirths in the GDR differed from the western definition at the expense of live births. The increase in the proportion of births in the weight category under $1000 \mathrm{~g}$ might be at least partly attributable to changes in documentation practices after unification. ${ }^{5}$ Despite improvements in perinatal care, a possible delay in implementing western registration practices, and the introduction of the extensive "Perinatal Quality Assurance Program" (Perinatalerhebung), maternal age also has to be taken into account. From 1991 to 1996 the average age of motherhood increased from 25.2 to 27.5 years in the new Länder whereas the figures for the old Länder were 28.3 and 29.3 years, respectively, with an increasing proportion of those aged 30 and above in both parts of Germany. ${ }^{11}$ This development indicates a converging process between the old and the new Länder in the relative proportion of birth weights at less than 1000 g. However, increasing maternal age may also be a factor in the upward shift in birth weight distribution. ${ }^{12}$

Furthermore it has to be noted that classification inconsistencies regarding live and stillbirths in the former GDR are said to have led to an underestimation of infant mortality as defined by WHO of about 0.1 per thousand. ${ }^{13}$ Thus, the "real" decline in infant mortality in the new Länder from 1990 is likely to be higher than that observed in this study.
KEY POINTS

- Infant mortality has improved in both east and west Germany since unification.

- The causes of the improvements differ, with the greatest reductions in neonatal mortality in the east and in postneonatal mortality in the west.

- The most likely explanations are improvements in perinatal care in both parts of Germany.

- Conclusions based on changes in aggregate measures, such as infant mortality, can be misleading.

BIRTH WEIGHT AND NEONATAL MORTALITY

This study provides important new insights into the health effects of German unification. It shows that there has been a slight change in the birth weight distribution in the new Länder that is reflected by a small increase in the numbers of very low birthweight infants recorded and also an increase in mean birth weight. The net effect of this change would, in the absence of other factors, have led to an increase in neonatal mortality or, at least, kept mortality at the 1991 level. Instead, neonatal mortality fell markedly by over 30 per cent. This was attributable to an improvement in survival at all birth weights but in particular among those with low and very low birth weight. Survival in this group is most amenable to medical interventions. The probable under recording of very low birthweight infants who die soon after birth in the earlier period suggests that the true effect may have been even greater than that shown by the data.

Improvements in survival among those born at less than $2500 \mathrm{~g}$ were also seen in the old Länder although not of this magnitude. The change in birth weight distribution in the west has contributed only slightly to the fall in neonatal mortality, while improvements in survival at each level of birth weight accounted for approximately 85 per cent of the overall improvement. Thus, changes in survival in the perinatal period are largely explained by differences in the quality of perinatal care, ${ }^{14}$ a finding that was also observed elsewhere. ${ }^{45}$ It is probable that this explanation holds true for the improvements in the new Länder as well, with an increase in birth weight specific survival accounting for an estimated 83 per cent of the overall improvement. In births of more than $1000 \mathrm{~g}$, changes in birth weight distribution did not make a major contribution to improvements in neonatal mortality and all improvements were attributable to improved birth weight specific survival rates in both, east and west.

The reform of the system of health care in the former GDR has increased availability of modern equipment and drugs, led to improvements in medical expertise and thus improved the quality of perinatal care. Other evidence indicates that shortages of modern treatments in the former communist bloc had consequences for health, such as the observation of a marked reduction in deaths from testicular 
cancer in the new Länder when modern chemotherapeutic agents became available after unification. ${ }^{16}$ However, the enormous decline in birth rates from 12 per thousand in 1989 to 5.1 per thousand in 1994 might have played some part as well in terms of better access to intensive care facilities similar to the in the situation in the Czech Republic. ${ }^{4}$

\section{POSTNEONATAL MORTALITY}

Turning to postneonatal mortality, quite different issues emerge. The increase in postneonatal mortality in the first year after unification may in part reflect the re-arrangement of the system of infant care in the new Länder. Although provisions for maternal, infant and child care in the former GDR and the old FRG were quite similar, at least in principle, they differed markedly in terms of institutional settings and incentives to make use of them. Utilisation of pre- and postnatal care in the former GDR was financially rewarded and controlled at the societal level while compliance with corresponding rules in the FRG was (and still is) left to individual responsibility. ${ }^{17}$ It seems to be very likely that replacing the GDR system after unification reduced use of postnatal care because of a delay in adapting to the new system and also because the system of social control, at least in terms of financial incentives, ceased to exist. However, as postneonatal mortality in particular is sensitive to socioeconomic factors, ${ }^{18}$ the immediate consequences of transition in terms of economic downturn and insecurity might have had some influence as well.

Although postneonatal mortality in the east recovered soon after 1991 to figures that are lower than those in the west, there is still room for further improvement, especially with regard to deaths caused by accidents and injuries that are amenable to preventive measures.

The increase in postneonatal mortality in the west after 1970 possibly reflected the impact of advice on sleeping position, which changed across north western Europe at that time. ${ }^{19}$ The rapid decline in postneonatal mortality in the old Länder in the early 1990s mirrors that seen in several other northern European countries that instituted a different policy at this time that was shown to be closely linked to sudden infant death (SIDS). In the former GDR there is only limited information on the frequency of SIDS with estimates of 10-27 per cent of all late neonatal deaths, and which increased during the $1980 \mathrm{~s}^{10}$

Obviously it is important to consider possible variation in coding of causes of death. Evidence suggests some problems with the reliability of selected adult cardiovascular deaths in Germany as reported by the official causes of death statistics. ${ }^{20}$ Regarding postneonatal deaths it was estimated that about $30 \%$ of SIDS cases are incorrectly coded as such in Germany. ${ }^{14}$ However, variation is greatest where more precise categories are used. The use of broad diagnostic groups, as in this paper, is designed to minimise any effect.

The large decline in deaths from congenital anomalies in the east seems improbable and raises concerns about a change in coding prac- tice. This is certainly possible although, however, in this analysis the year 1991 was chosen as baseline to reduce any effect that might have arisen from such changes implemented in October 1990. ${ }^{21}$ Before a real change is dismissed it is necessary to examine other possibilities. One is a real improvement in medical care by means of improved quality of birth and disease management because of increased prenatal screening and improved treatment. $^{22}$ A second could be an improvement in nutrition since unification, especially in folic acid consumption given the known relation between folic acid and neural tube defects. ${ }^{23}$ Finally, east Germany experienced a dramatic fall in birth rates from 1989, which might be expected to have some effect because of increased access to health care facilities as discussed earlier. These issues are subjects of ongoing research.

\section{POLICY IMPLICATIONS}

These findings have important implications for policy. The study shows that, since unification, both parts of Germany underwent a complex process that has led ultimately to convergence of parameters of infant health. The most recent data suggest that there is still some room for further improvement in the new Länder, in particular in terms of a neonatal mortality rate that still remains higher than in the west. However, increased survival of infants at very low birth weights because of improvements in medical care raises questions about the risk of severe disabilities or a simple postponing of death to a later period of life, as suggested by the observation of a shift from perinatal mortality to neonatal mortality. ${ }^{24}$ The proportion of low birth weight infants in both parts of Germany is still much higher than those reported for the Nordic countries, ${ }^{25}$ suggesting that policy should concentrate on preventive rather than curative measures to improve infant mortality further.

This paper demonstrates the scope for monitoring not only regional and east-west differences in Germany but also what can be done using detailed analysis of existing data. However, studies on aggregate data such as this can only indicate the existence of a problem and suggest possible avenues for further exploration. It would for example be useful to look at geographical and social variation within east and west. Especially the peak in postneonatal mortality in 1990/91 deserves a closer look to the underlying causes. What is now required in Germany is a system to identify specific amenable factors, such as the confidential inquiries into neonatal deaths that have been established elsewhere.

Funding: EN is supported by a European Commission TMR Fellowship, no FMBICT983062.

Conflicts of interest: none.

1 Grünheid E, Mammey U. Bericht 1997 über die demographische Lage in Deutschland. $Z$ Bevölkerungswissenschaft 1997;22:377-480.

2 Bundesregierung. Fahresbericht der Bundesregierung zum Stand der Deutschen Einheit 1998. Bundestags-Drucksache 13/10823. Bonn: 1998.

3 ECOHOST. Childhood injuries: a priority area for the transition countries of Central and Eastern Europe and the newly independent states. London: LSH\&TM, 1998. 
4 Koupilová I, McKee M, Holcik J. Neonatal mortality in the Czech Republic during the transition. Health Policy 1998;46:43-52.

5 Dammann O, Hellwege HH, Sommer B. Low birthweight in Germany 1990-92. Paediatr Perinat Epidemiol 1996;10: 130-5.

6 Statistisches Bundesamt. Todesursachen in Deutschland. Reihe 4. Wiesbaden: Statistisches Bundesamt, 1999.

7 Health for All Data Base European Region. Copenhagen: World Health Organization, Regional Office for Europe, June 1998.

8 Ministerium für Gesundheitswesen der DDR, ed. Das Gesundheitswesen der Deutschen Demokratischen Republik. Berlin: Institut für Medizinische Datenverarbeitung und Statistik, 1980-1989.

9 Microsoft Corporation. Microsoft Excel Version 97.

10 Bundesminister für Gesundheit, ed. Indikatoren zum Gesundheitszustand der Bevölkerung in der ehemaligen DDR. Baden-Baden: Nomos-Verlagsgesellschaft, 1993.

11 Sommer B. Eheschließungen, Geburten und Sterbefälle 1996. Wirtschaft und Statistik 1998;3:232-8.

12 Bonellie SR, Raab GM. Why are babies getting heavier? Comparison of Scottish births from 1980 to 1992 . BMF Comparison of

13 Casper W, Wiesner G, Bergmann KE, eds. Mortalität und Todesursachen in Deutschland. Berlin: RKI-Heft 10/1995.

14 Brand A, Bredehöft J, Brand H. Verbesserung der Vollständig keit und Validität der flächendeckenden Dokumentation angeborener Fehlbildungen im Rahmen der Perinatalerhebung. Bielefeld: LÖGD, 1999.

15 Kalter HD, Na Y, O'Campo P. Decrease in infant mortality in New York City after 1989. Am F Public Health 1998;88: 816-20.
16 Becker N, Boyle P. Decline in mortality from testicular cancer in West Germany after reunification. Lancet 1997;350: 744 .

17 Henning A. Mother and child care. In: Light DW, Schuller A, eds. Political values and health care: the German experience. Cambridge, MA: MIT Press, 1986:467-86.

18 Leon DA, Vågerö D, Olausson PO. Social class differences in infant mortality in Sweden: comparison with England and Wales. BMF 1992;305:687-91.

19 McKee M, Fulop N, Bouvier P, et al. Preventing sudden infant deaths - the slow diffusion of an idea. Health Policy 1996;37:117-35.

20 Giersiepen K, Greiser E. Verschlüsselung von Todesursachen für Mortalitätsstatistiken - Vergleich .. von Signierergebnissen in verschiedenen statistischen Ämtern der Bundesrepublik Deutschland und West-Berlins. Öffentliches Gesundheitswesen 1989;51:40-7.

21 Brückner G. Todesursachen 1990/91 im vereinten Deutschand. Wirtschaft und Statistik 1993;4:257-78.

22 Petrini J, Damus K, Johnston RB. Trends in infant mortality attributable to birth defects-United States, 1980-1995. MMWR Morb Mortal Wkly Rep 1998;47:773-8.

23 Czeizel AE. Congenital abnormalities are preventable. Epidemioloy 1995;6:205-6.

24 Cartlidge PHT, Stewart JH. Effect of changing the stillbirth definition on evaluation of perinatal mortality rates. Lancet 1995;346:486-8.

25 Bjerkedal T, Irgens LM, Daltveit AK. Occurrence and survival of low birthweight births in the Nordic countries, 1980-1994. In: Health statistics in the Nordic countries. NOMESCO Report no 49. Reykjavik: Nordic Medico Statistical Committee, 1997:190-215. 